\title{
YKL-40 IN SERA OF BREAST TUMOR PATIENTS
}

\author{
Maria Kazakova ${ }^{1}$, Tanya Deneva ${ }^{2}$, Vanya Uzunova ${ }^{3}$, Victoria Sarafian ${ }^{1}$ \\ 1) Department of Medical Biology \\ 2) Department of Clinical Laboratory \\ 3) Clinic of Thoraco-Abdominal Surgery \\ Medical University - Plovdiv, Bulgaria
}

\section{SUMMARY}

YKL-40, also known as human cartilage glycoprotein 39 , is a member of the "mammalian chitinase-like proteins", but lacking of chitinase activity. Increased variations in serum concentrations are associated with inflammatory processes and several types of cancer.

In this study we evaluated serum YKL-40 levels in healthy controls and in women with benign and malignant breast tumors.

YKL-40 serum levels were measured by enzyme-linked immunosorbent assay - ELISA in 32 patients. The effect of the various factors was analyzed using correlation and regression analyses simultaneously determining the size and direction of correlation. The level of statistical significance of null hypothesis was $\mathrm{P}<0.05$.

Our study showed that serum YKL-40 level in breast carcinoma was significantly higher than the concentration in healthy controls $(\mathrm{p}<0.01)$. The changes in protein levels were higher than $25 \%$. Serum YKL-40 increased with age $\left(\mathrm{r}_{\mathrm{xy}}=0.46\right)$. The correlation between glycoprotein quantity and age was positive, but feeble.

This investigation is first in Bulgaria to demonstrate significantly elevated serum YKL-40 level in breast carcinoma compared to women with benign breast tumors and healthy controls. Longitudinal studies are needed to confirm YKL-40 as a potential and reliable biomarker.

Key words: YKL-40, ELISA, breast tumor

\section{INTRODUCTION}

Cancer research is focused on identifying the molecular and genetic changes that cause malignant transformation. Molecular targeted therapy for advanced solid tumors directed towards receptors for growth factors or signaling and regulatory molecules has been proven to be successful (1).

According to the American Cancer Society estimated cancer death in women for 2009 is 269,800 . Breast cancer accounts for $15 \%$ of all cases of death (National Cancer Society). Currently available breast cancer screening tools such as mammography and breast examination miss $10-40 \%$ of early breast cancers (2).
The development of noninvasive techniques that could distinguish women with or without breast cancer is of vast importance. The advantages of the markers include early detection or screening, discriminating benign from malignant disease, histological differentiation, and early prognosis (3).

YKL-40 is an extracellular matrix glycoprotein with a high sequence homology to the proteins of the chitinase like family, but without chitinase activity (4). The plasma protein is secreted by macrophages, chondrocytes, activated neutrophils, differentiated monocytes, vascular smooth muscle cell and cancer cells. Increased serum concentrations are associated with inflammatory processes and several types of cancer.

The binding site of YKL-40 to receptors on the cell surface is not known yet and the biological function of the protein is only poorly understood.

Elevated serum level of YKL-40 has a potential prognostic value in several cancers including breast (1), ovary $(5,6,7)$, colorectal $(8)$, glioblastoma $(9,10)$, melanoma $(11)$. In these studies, increased variations in serum protein are associated with short recurrence and short overall survival.

It is assumed that YKL-40 has a role in cancer proliferation, differentiation, metastatic potential, angiogenesis, however, these effects are not obtained yet in vivo.

On the other hand, serum YKL-40 is not specific for cancer only. Elevated values are found in processes characterized by acute or chronic inflammation and intensive extracellular tissue remodeling - rheumatoid arthritis $(12,13)$, osteoarthritis $(14,15)$, inflammatory bowel disease (16), giant cell arthritis (17), pulmonary sarcoidosis (18), liver fibrosis (19).

The aim of the present study was to determine serum YKL-40 levels in women with benign and malignant breast tumors and healthy controls. This is the first study in Bulgaria investigating YKL-40 expression.

\section{MATERIALS AND METHODS}

The control group consisted of 10 healthy female volunteers aged (18-50) without cancer or joint, liver, metabolic, or endocrine diseases. Clinical and routine hematological, biochemical and coagulation tests were performed to assess their health status. 
The target group consisted of 14 women with fibroadenoma and 8 women with breast carcinoma. The study was approved by the University Ethics Committee. Informed content was asked and achieved from all examined individuals according to the Helsinki Declaration.

Venous blood samples were collected from patients before surgery or chemoradiation in the morning $(4.5 \mathrm{mmol} / 1$ blood, Monovette, Sarstedt) as atraumatically as possible after a 12-hour fasting and 30-minute rest immediately prior to testing. The samples were centrifuged at $2500 \mathrm{rpm}$ for 10 minutes. The serum was kept at $-20^{\circ} \mathrm{C}$ for no more than a month before analysis.

Serum YKL-40 concentrations were determined by a two-site, sandwich-type, enzyme-linked immunosorbent assay (ELISA) (Quidel Corporation, Cat. No. 8020) according to the manufacturer's instructions. The validation of the method was performed in compliance with the international standard of quality and competence of medical laboratories (BDS/EN/ISO 15189). The method shows high precision; the results are consistent with the recommended minimal non-reproducibility (intra-assay $\mathrm{CV}<10 \%$; inter-assay $\mathrm{CV}<12 \%$ ) for ELISA in studying YKL-40 as given by the manufacturer. The detection limit of the YKL-40 assay was $20.0 \mathrm{ng} / \mathrm{ml}$. All samples were analysed in duplicates.

Microsoft Excel 2000 and SPS 12.0 (Windows XP) were used to analyze the results. The level of statistical significance of hull hypothesis was $\mathrm{P}<0.05$. The effect of the various factors was analyzed using correlation and regression analyses simultaneously determining the size and direction of correlation.

\section{RESULTS}

Our investigation revealed a mean value 41,11 (20-59) $\mathrm{ng} / \mathrm{ml}$ of serum YKL-40 in healthy subjects. The median serum concentration of YKL-40 in patients with breast carcinoma was 100,27 (36-169) $\mathrm{ng} / \mathrm{ml}$ and it was significantly higher compared to the level in women with fibroadenoma 44,58 (2287) $\mathrm{ng} / \mathrm{ml}(\mathrm{P}<0.001)$.

Obviously, the results show that serum YKL-40 level in breast carcinoma is significantly higher than the concentration in healthy controls. The results are presented on Fig. 1.

Next, we determined the correlation between age and serum YKL-40 level in all patients aged 18-75. It was constructed by linear regression with the glycoprotein as the dependent variable and age as the explanatory variable. Serum YKL-40 increased with age $\left(\mathrm{r}_{\mathrm{xy}}=0.46\right)$. The correlation was positive but feeble.

\section{DISCUSSION}

Different research groups showed that in healthy adults (aged 18-79), the median level of serum YKL-40 determined by ELISA was $43 \mathrm{mg} / 1$ (range 20-184 $\mathrm{mg} / \mathrm{l}$ ) (20).

At the cellular level YKL-40 protein expression is high in tissues characterized by rapid proliferation, differentiation, and undergoing morphogenetic changes. YKL-40 protein expression is widely distributed at specific time points in early developing human musculoskeletal system. (21). Recent studies show that the expression of YKL-40 in normal adult tissues is feeble and show positive relation with metabolic activity (22).

Our results revealed that serum protein level in healthy adults was $41,11 \mathrm{ng} / \mathrm{ml}$ - values close to the ones observed in the Danish population. We have found that serum YKL-40 increased with age $\left(r_{x y}=0.46\right)$, but the correlation was feeble. According to Johansen et al. (2008), serum YKL-40 increased with age but in the normal reference interval. Aging is associated with enhanced inflammatory activity reflected by increased circulating levels of TNF- $\beta$, IL-6, cytokine antagonists and acute phase proteins (23).

It is assumed that YKL-40 could participate not only in normal cell functions but also in inflammation and neoplastic processes. The complete biological function of YKL-40 in cancer is not clear. It has been hypothesized that the protein exerts growth properties on chondrocytes, synovial cells and fibroblasts where it works synergistically with insulin-like growth factor $(24,25)$. It could not be excluded that YKL-40 might act as a growth factor for cancer cells, too.

Another possibility is that YKL-40 protects cancer cells from undergoing apoptosis. It is also called "breast regression protein" (Brp-39), because it induces mammary involution in mice a few days after weaning (26).

It is well known that the programmed cell death is a major process in mammary involution. In fact, YKL-40 determines which cells to survive during the drastic tissue remodeling and acts as a protective molecule (14).

Obviously, our study showed that serum YKL-40 level in breast carcinoma is significantly higher than the concentration in women with fibroadenoma $(p<0.01)$. The results are presented in Table 1.

The changes in serum YKL-40 levels in our study are higher than 25\%. Johansen et al., (2006) suggested that changes in serum YKL-40 concentration higher than $20 \%$ should be indicative of elevated serum range.

It is believed that increased expression of YKL-40 may improve the identification of women at increased breast cancer risk. The protein was determined in tissue, nipple aspirated fluid and serum of 118 women - 61 healthy subjects, 10 with precancer and 47 with breast cancer. It was assessed that YKL-40 was concentrated in nipple aspirated fluid relative to serum. Nipple aspirated fluid levels of YKL-40 were higher in precancers than either levels from healthy women. It was observed that YKL-40 expression in precancerous tissue which trended higher than in normal or cancerous tissue (2).

Cancer development depends on the interaction between cancer cells and the extracellular matrix components. The immunohistochemical analysis of YKL-40 expression in 
biopsies from breast cancer (27) and colorectal cancer (28) are positive for protein expression. Furthermore, the macrophages and neutrophils surrounding the breast and colorectal cancer cells also express YKL-40.

YKL-40 is not specific for all types of cancer disease. It was shown that at the time of the first cancer diagnosis $16-74 \%$ of the patients had elevated serum YKL-40 levels. However, in patients with metastatic cancer, serum YKL-40 levels increased $39-83 \%$ at the time of diagnosis (29).

It is considered that serum YKL-40 could be more useful for monitoring disease and progression in cancer patients after treatment, providing independent information of survival $(28,10,21)$.

A study by Yamac et al., (2008) demonstrated that the median serum YKL-40 concentration in patients with locally advanced breast cancer was $149.5 \mathrm{mg} / \mathrm{ml}$ and it was higher than levels observed in healthy female controls. It was suggested that YKL-40 may be a useful prognostic indicator of outcome for patients with locally advanced breast cancer (31).

The serum levels of an epithelial growth factor and YKL-40 in relation to outcome in 100 patients with their first diagnosis of recurrent breast cancer was assessed. Elevated serum YKL-40 concentrations were found in 30\% of the patients and epithelial growth factor in $32 \%$ of the subjects. It was found that high serum levels of epithelial growth factor and YKL-40 reflected increased aggressiveness and decreased response to anthracycline-based therapy. It was suggested that high serum YKL-40 and epithelial growth factor independently identified patients with metastatic breast cancer with a poor prognosis (1).

YKL-40 facilitates cell attachment and migration of vascular endothelial cells, which is an indication that the protein may function in angiogenesis (13).

Immunohistochemical analysis of human breast cancer showed a correlation between YKL-40 expression and blood vessel density. These results are another evidence for the angiogenic activities of YKL-40 in cancer development (32).

\section{CONCLUSION}

In conclusion, our study is the first in Bulgaria to show significantly elevated serum YKL-40 level in breast carcinoma compared to women with benign breast tumors and healthy controls. Prospective investigations are aimed at evaluation of YKL-40 as a reliable biomarker and an appropriate target for development of anticancer therapy.
Table 1. Comparative data on YKL-40 serum levels in breast fibroadenoma and carcinoma

\begin{tabular}{|c|c|c|}
\hline Criteria & Fibroadenoma & Carcinoma \\
\hline Number of patients & 14 & 8 \\
\hline $\begin{array}{c}\text { Concentration } \\
\text { of YKL-40 }(\mathrm{ng} / \mathrm{ml})\end{array}$ & 41,11 & 100,27 \\
\hline SD & 12,61 & 80,33 \\
\hline P-value & $<0,02$ & $<0,02$ \\
\hline
\end{tabular}

Figure 1. Serum levels of YKL-40 in healthy subjects and patients with breast tumors

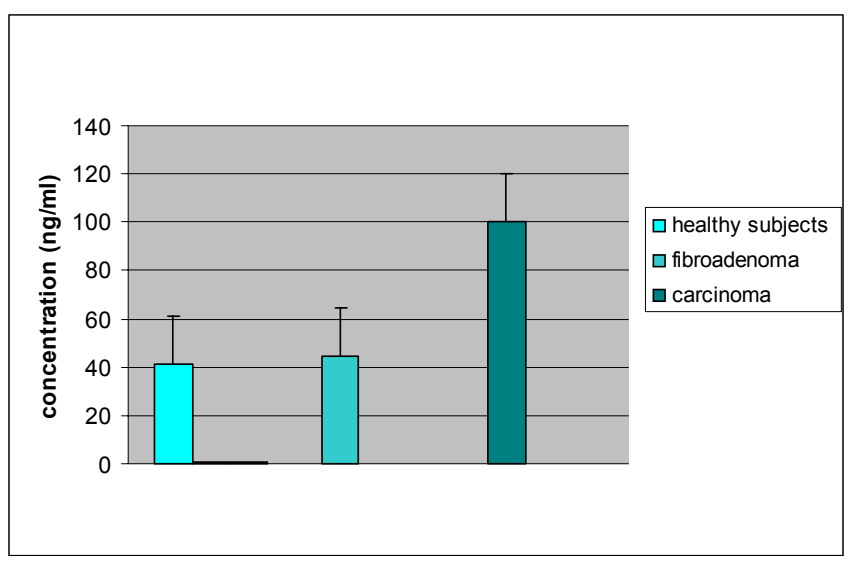


Fig. 2. Summarized biological functions of YKL-40

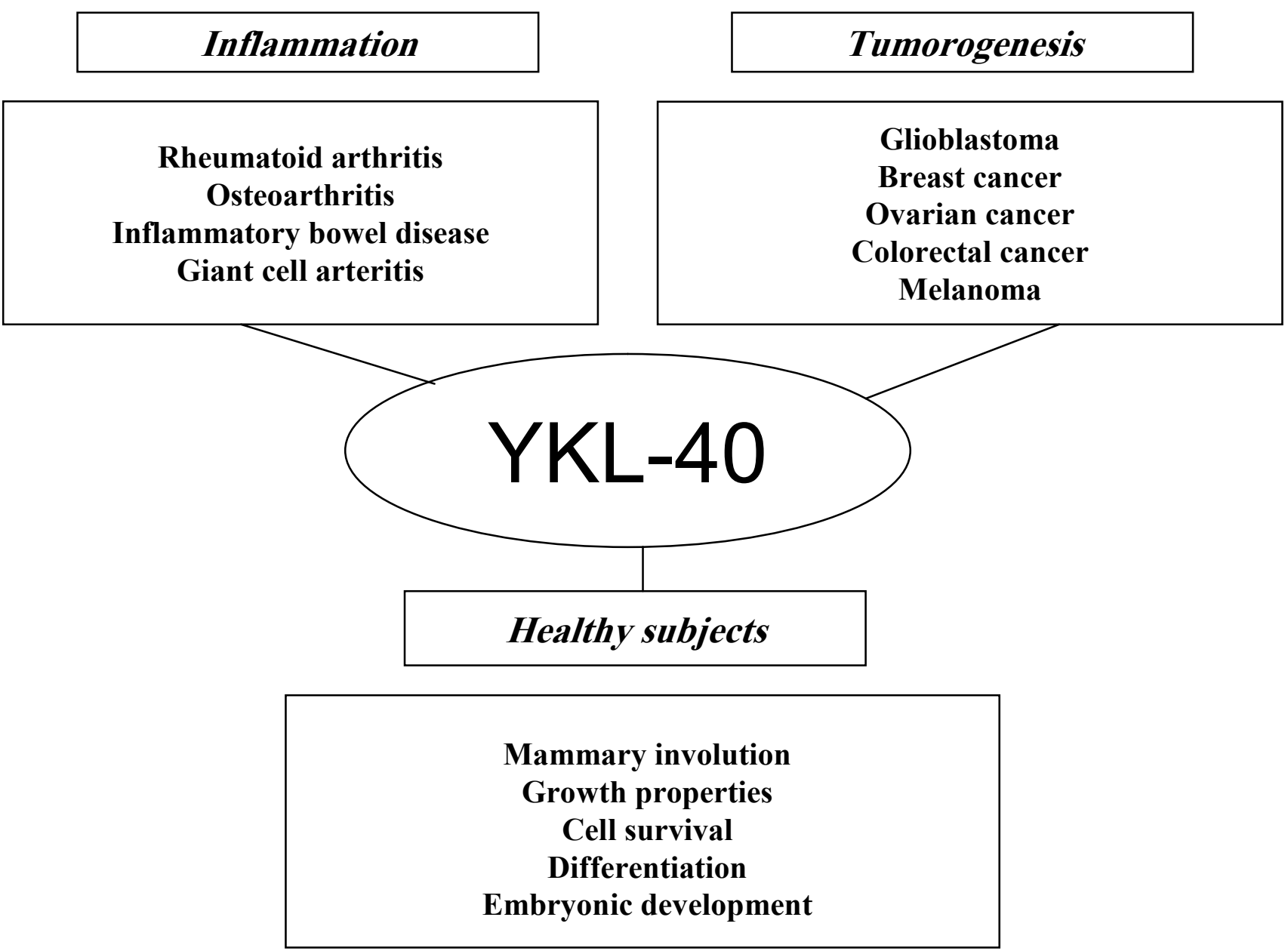

Acknowledgments:

The study is supported by grants No.-1/2009 and No.-5/2008 from Medical University - Plovdiv.

\section{REFERENCES:}

1. Jensen BV, Johansen JS, Price PA. High levels of serum HER-2/neu and YKL40 independently reflect aggressiveness of metastatic breast cancer. Clin Cancer Res, 2003; 9: 4423-4434.

2. Qin W, Zhu W, Schalter L., et al. Increased expression of the inflammatory protein YKL-40 in precancers of the breast. Int J Cancer, 2007; 121: 1536-1542.

3. Zhong L, Ge K, Zu J., et al. Autoantibodies as potential biomarkers for breast cancer. Breast Cancer Res, 2008; 10: doi:10.1186/bcr2091.

4. Hakala BE, White C, Recklies AD. Human cartilage gp-39, a major secretory product of articular chondrocytes and synovial cells, is a mammalian member of a chitinase protein family. J Biol Chem, 1993; 268: $25803-25810$.

5. Hrgdall EVS, Johansen JS, Kjaer SK., et al. High plasma YKL-40 level in patients with ovarian cancer stage III is related to shorter survival. Oncol Rep, 2003; 10: 15351538 .

6. Hrgdall E, Ringsholt M, Hwgdall C., et al. YKL-40 tissue expression and plasma levels in patients with ovarian cancer. BMC Cancer, 2009; 9: 8 doi: 10.1186/1471-24079-8

7. Dupont J, Tanwar MK, Thaler HT., et al. Early detection and prognosis of ovarian cancer using serum YKL-40. J Clin Oncol, 2004; 22: 3330-3339.

8. Cintin C, Johansen JS, Christensen IJ., et al. Serum YKL-40 and colorectal cancer. Br J Cancer, 1999; 79: 1494-1499.

9. Tanwar MK, Gilbert MR, Holland EC. Gene expression microarray analysis reveals YKL-40 to be a potential serum marker for malignant character in human glioma. Cancer Res, 2002; 62: 4364-4368.

10. Hormigo A, Gu B, Karimi S., et al. YKL-40 and matrix metalloproteinase-9 as potential serum biomarkers for patients with high-grade gliomas. Clin Cancer Res, 2006; 


\section{2: 5698-5704.}

11. Schmidt H, Johansen JS, Gehl J., et al. Elevated serum levels of YKL-40 is an independent prognostic factor for poor survival in patients with metastatic melanoma. Cancer, 2006; 106: 1130-1139.

12. Volck B, Johansen JS, Stoltenberg M., et al. Studies on YKL-40 in knee joints of patients with rheumatoid arthritis and osteoarthritis. Involvement of YKL-40 in the joint pathology. Osteoarthritis Cartilage, 2001; 9: 203-214.

13. Johansen JS. Studies on serum YKL40 as a bioarker in diseases with inflammation, tissue emodelling, fibroses and cancer. Dan Med Bull, 2006; 53:172-209.

14. Kawazaki M, Hasegawa Y, Kondo S., et al. Concentration and localization $\mathrm{f}$ YKL-40 in hip joint diseases. J Rheumatol, 2001; 28: 341-345.

15. Zivanovic. S, Rachov LP, Vojvodic D, Yucetie D. Human cartilage glycoprotein 39 - biomarker of joint damage in knee osteoarthritis. International Orthopaedics, 2009, 33: 1165-1170.

16. Vind I, Johansen JS, Price PA, Munkholm P. Serum YKL-40, a potential new marker of disease activity in patients with inflammatory bowel disease. Scand J Gastroenterol, 2003; 38: 599-605.

17. Johansen JS, Baslund B, Garbarsch C., et al. YKL-40 in giant cells and macrophages from patients with giant cell artheritis. Arthritis Rheum, 1999; 42: 26242630.

18. Johansen JS, Milman N, Hansen M., et al. Increased serum YKL-40 in patients with pulmonary sarcoidosis. A potential marker of disease activity? Resp Med, 2005; 99: 396-402.

19. Nrjgaard C, Johansen JS, Christensen E., et al. Serum levels of YKL40 and PIIINP as prognostic markers in patients with alcoholic liver disease. J Hepatol, 2003, 39: 179-186.

20. Johansen JS, Lottenburger T, Nielsen HJ., et al. Weekly and long-time variation in serum concentrations of YKL40 in healthy subjects. Cancer Epidemiol Biomarkers Prev, 2008; 5: 2603:2608.

21. Johansen JS, Hryer PE, Larsen LA, et al. YKL-40 protein expression in the early developing human musculoskeletal system. J Histochem Cytochem, 2007; 55: 12131128.

22. Ringsholt M, Hrgdall EVS, Johansen JS., et al. YKL-40 protein expression in normal adult human tissues - an immunohistochemical study. J Mol Hist, 2007; 38: 33-43.

23. Bruunsgaard H, Pedersen M, Pedersen BK. Aging and proinflammatory cytokines. Curr Opin Hematol, 2001; 8: 131-136.

24. De Ceuninck F, Gaufillier S, Bonnaud A., et al. YKL-40 (Cartilage gp39) induces proliferative events in cultured chondrocytes and synoviocytes and increases glycosaminoglycan synthesis in chondrocytes. Biochem Biophys Res Commun, 2001; 285: 926-931.

25. Recklies AD, White $\mathrm{C}$, Ling $\mathrm{H}$. The chitinase 3-like protein human cartilage glycoprotein 39 (HC-gp39) stimulates proliferation of human connective tissue cells and activates both extracellular signal- regulated kinase- and protein kinase Bmediated signalling pathways. Biochem J, 2002; 365: 119-126.

26. Mohanty AK, Singh G, Paramasivam M., et al. Crystal structure of a novel regulatory $40-\mathrm{kDa}$ mammary gland protein (MGP-40) secreted during involution. J Biol Chem, 2003; 278: 1445114460.

27. Roslind A, Johansen JS. YKL-40: a novel marker shared by chronic inflammation and oncogenic transformation. Methods Mol Biol, 2009; 511: 159-184.

28. Cintin C, Johansen JS, Christensen IJ., et al. Highserum YKL-40 level after surgery for colorectal carcinoma is related to short survival. Cancer, 2002; 95: 26774.

29. Johansen JS, Jensen BV, Roslind A, et al. Serum YKL-40, a new prognostic biomarker in cancer patients? Cancer Epidemiol Biomarkers Prev, 2006; 15: 194202.

30. Ringsholt M, Hwgdall EVS, Johansen JS., et al. YKL-40 protein expression in normal adult human tissues an immunohistochemical study. J Mol Hist, 2007; 38: 33-43.

31. Yamac D, Ozturk B, Coskun U., et al. Serum YKL-40 levels as a prognostic factor in patients with locally advanced breast cancer. Advance in Therapy, 2008; 25 : 801-809.

32. Shao R, Hamel K, Petersen L., et al. YKL-40, a secreted glycoprotein, promotes tumor angiogenesis. Oncogene, 2009; 28: 4456-4468.

\author{
Address for correspondence: \\ Maria Hristova Kazakova \\ Department of Medical biology, Medical University of Plovdiv \\ 15A V. Aprilov Blvd., 4000 Plovdiv, Bulgaria \\ Tel. $+359 / 42 / 602993$ \\ e-mail: kazakova25@abv.bg
}

